\title{
Faces da produção agrícola na Amazônia mato-grossense: tipos de exploração, origem dos agricultores e impactos na conservação ambiental em Alta Floresta (MT)
}

\section{The implications of agricultural production in the Amazon Forest of Mato Grosso state: kinds of exploration, origin of the farmers and environmental impacts in Alta Floresta (MT)}

Isabelle Bonini - bióloga, mestranda em Biodiversidade e Agroecossistemas Amazônicos da Universidade do Estado de Mato Grosso (UNEMAT), Brasil - Mato Grosso - Alta Floresta, e-mail: isabelle_biologa@hotmail.com

Marcos José Gomes Pessoa - Biólogo, mestrando em Biodiversidade e Agroecossistemas Amazônicos da Universidade do Estado de Mato Grosso (UNEMAT), Brasil - Mato Grosso - Alta Floresta, e-mail: marcos-af@hotmail.com

Santino Seabra Junior - Engenheiro agrônomo, mestre e doutor em Agronomia (Horticultura) pela UNESP, Prof. Adjunto da UNEMAT, Brasil - Mato Grosso - Cáceres, e-mail: santinoseabra@, hotmail.com

\section{Resumo}

O processo de colonização da Amazônia mato-grossense foi marcado pela ocupação e uso desordenado do território. Os colonos, oriundos principalmente da região Sul, trouxeram consigo várias técnicas de cultivo e modelos de exploração até então não praticados na região, estabelecendo, desta maneira, um novo cenário socioeconômico e ambiental. As faces desse novo sistema de produção agrícola constituem-se como motivo de muita discussão no meio científico. Com base neste cenário, objetivou-se realizar um referencial bibliográfico dessas interfaces considerando-se os tipos de exploração, a origem dos agricultores e os possíveis impactos ambientais para a referida região.

\section{Palavras-chave}

Agropecuária. Amazônia Legal. Colonização. Economia. Extrativismo.

\begin{abstract}
The process of colonization of the Amazon Forest in the state of Mato Grosso was characterized by disorderly occupation and use of territory. The settlers, coming mainly from the south of Brazil, bring with them a lot of farming techniques and exploration models which were unkown in this region, establishing a new environmental and socioeconomic scenario. The implications of this new system of agricultural production have been largely discussed in the academy. Based in this scenery, we aimed to raise bibliographical references of these implications, taking in account the kinds of exploration, the origin of the farmers and the environmental impacts for the region.
\end{abstract}

\section{Keywords}

Agriculture. Legal Amazon. Colonization. Economy. Extraction. 


\section{INTRODUÇÃO}

A Floresta Amazônica é considerada o lar da maior diversidade do mundo, destacando-se pela riqueza de espécies com potencial para uso na agricultura, melhoramento genético e domesticação, incluindo espécies florestais, frutíferas, palmáceas, forrageiras, medicinais e industriais. Em função da grande diversidade das florestas tropicais, dos riscos de perdas de populações naturais e dos conhecimentos limitados sobre seus recursos, reconhece-se que esses ecossistemas são prioritários para a conservação e uso econômico sustentável.

Está situada na Região Centro-Norte da América do Sul e ocupa áreas do território de nove países do continente: Brasil, Bolívia, Peru, Equador, Colômbia, Venezuela, Guiana, Suriname e Guiana Francesa. A maior parte do ecossistema, correspondente a 66\% da área, encontra-se em território brasileiro (SOUZA, 2010).

A "Amazônia Brasileira", como era anteriormente tratada, passou a ser chamada no Brasil, a partir da década de 1950, de Amazônia Legal. O conceito essencialmente político aumentou para 1,3 milhão $\mathrm{km}^{2}$ a área da Amazônia brasileira, uma vez que incorporou uma longa faixa de vegetação de transição com cerca de 700 mil km², composta por ecossistemas diferenciados, como os cerrados (fronteira sul da Amazônia) e os campos do norte (típicos nos estados de Roraima, Pará e Amapá) (SOUZA, 2010). Este conceito foi criado pelo governo brasileiro com o intuito de melhor planejar o desenvolvimento social e econômico da região amazônica. Procurou-se, por meio desse zoneamento territorial, concentrar regiões da floresta amazônica com semelhantes problemas econômicos, políticos e sociais, levando-se em consideração análises geográficas, estruturais e conjunturais (PROCÓPIO, 2005).

A Amazônia Legal engloba, atualmente, todos os estados brasileiros pertencentes à Bacia Amazônica e abrange todos os que possuem ou tangenciam trechos da Floresta Amazônica. Atualmente, compreende os estados do Pará, Amazonas, Maranhão, Tocantins, Mato Grosso, Acre, Amapá, Rondônia e Roraima. A sua superfície é de aproximadamente $5.217 .423 \mathrm{~km}^{2}$ e corresponde a cerca de $61 \%$ do território brasileiro. Abriga uma população em torno de 20 milhões de habitantes, dos quais 60\% vivem em áreas urbanas (SOUZA, 2010). É depositária da maior extensão de florestas tropicais do planeta e detentora de uma imensa variedade biológica de ecossistemas, espécies e recursos energéticos, emergindo como tema de especial interesse para vários campos das ciências políticas (PROCÓPIO, 2005). 
Há indícios de que o processo de ocupação da Amazônia por populações eurodescendentes teve início já nos tempos da conquista e colonização do Brasil. Entretanto, até o início do século XX, a floresta ainda era vista como

[...] um imenso maciço natural até certo ponto intransponível, como se o peso de sua constituição física - forte calor e umidade, floresta densa e complexa trama fluvial - funcionasse como uma espécie de obstáculo à 'penetração e ocupação'. (HUERTAS, 2009, p. 45).

Atualmente, nota-se um crescimento econômico bastante acelerado, direcionado aos estados de Goiás, Mato Grosso, Mato Grosso do Sul, Distrito Federal, Tocantins e Rondônia, devido à expansão da agricultura comercial, principalmente das culturas de grãos e da pecuária. Tais mudanças podem ocasionar graves consequências ecológicas e sociais, podendo anular as vantagens obtidas com o aumento da oferta agropecuária, especialmente se considerarmos a alta volatilidade dos preços das commodities agrícolas no mercado internacional (HOGAN, 2000).

Dentro desse contexto, o presente artigo traz um referencial bibliográfico do avanço da fronteira agrícola na Amazônia mato-grossense, a partir do processo de incorporação da economia regional nos cenários nacional e internacional. Aborda também a necessidade de entender os tipos de exploração, as origens dos agricultores e os possíveis impactos ambientais na configuração da estrutura urbana regional.

\section{PROCESSOS DE OCUPAÇÃO, TIPOS DE EXPLORAÇÃO E DESENVOLVIMENTO NA AMAZÔNIA MATO-GROSSENSE}

O movimento inicial de ocupação da região amazônica se deu através do extrativismo vegetal, que consistiu na exploração das espécies denominadas "drogas do Sertão", fornecendo às populações locais produtos para exportação e para sua subsistência (SANTOS, 1980). Dentre os principais produtos extrativos que foram (e ainda são) de suma importância para a economia regional estão o cacau, a borracha (seringueira), a castanha-do-brasil e a madeira. Outros produtos extrativos, como as gomas não-elásticas, fibras, sementes oleaginosas, tanantes, medicinais e tóxicos também têm destaque na economia regional (HOMMA e KINGO 1990). Dentre esses produtos, o que obteve maior representatividade para a exportação foi o cacau, que aos poucos se tornou o eixo da economia regional, da mesma forma que, em épocas distintas, outros produtos lideraram as 
exportações, como o açúcar no Nordeste, o café no Sul e a borracha na própria Amazônia (SANTOS, 1980).

A ocupação do território mato-grossense sempre esteve associada à exploração de um produto de grande interesse ao mercado externo, como o ouro, o diamante e a borracha, dentre outros. Historicamente, a Amazônia brasileira teve a sua presença garantida no cenário nacional graças aos recursos que podiam ser extraídos de sua floresta. A seringueira, que tem origem na Amazônia, já participou como segundo produto na pauta das exportações brasileiras por cerca de 30 anos e, ainda hoje, continua tendo expressividade econômicosocial (HOMMA e KINGO, 1990). Até 1930, a extração de erva-mate era a atividade predominante, promovendo um crescimento expressivo na região sul (atual Mato Grosso do Sul). Na porção norte do estado (atual Mato Grosso), a densidade populacional era baixa, devido à pequena ocupação humana em seu vasto território. Após 1930, o espaço geográfico do Mato Grosso sofreu algumas mudanças relacionadas à produção e/ou extração de produtos do setor primário (agricultura e extrativismo). Ainda assim, a ocupação da região norte do estado era baixa, caracterizando-a como uma área de "vazio demográfico" (PERIPOLLI, 2002).

O processo de ocupação da Amazônia redirecionou os processos migratórios no Brasil, que até a década de 1970, concentravam-se em direção ao Sul e Sudeste do país. Em meados da década de 1960, diante das reformas governamentais implementadas sob o princípio de "mudar para se manter", a Amazônia passou a despertar interesse do Estado, que se encontrava em meio a uma crise fundiária. A “Operação Amazônia”, fundamentada em um conjunto de leis criadas no período de 1966 a 1977, intensificou o fluxo populacional em direção ao Centro-Oeste e Norte, devido principalmente aos incentivos fiscais cedidos pelo governo para a colonização dessas áreas (CUNHA, 2006). O objetivo desta operação era ampliar a infraestrutura da região. Neste período foram fundados o Banco da Amazônia e a Superintendência do Desenvolvimento da Amazônia (Sudam), importantes para a expansão do sistema de incentivos fiscais voltados à colonização da região amazônica (JATENE, 1983).

A dinâmica socioeconômica da Amazônia mato-grossense foi caracterizada por um intenso processo de ocupação demográfica e econômica, acarretando sérios impactos na estrutura produtiva e fundiária regional. No início da década de 1970, os modelos de colonização e modernização agrícola na Amazônia eram baseados nos princípios da Revolução Verde, visando o aumento da produção e da produtividade através da abertura de novas áreas e da busca por tecnologias agrícolas mais eficientes. Este modelo de desenvolvimento, subsidiado pelo 
governo através de incentivos fiscais, possibilitou a entrada massiva de grandes empreendimentos do setor agropecuário na Amazônia, provocando mudanças significativas na organização da produção e, consequentemente, desestabilizando a agricultura familiar (LOUREIRO, 2002).

Nesta mesma década, a Amazônia mato-grossense possuía apenas uma aglomeração urbana, denominada Porto dos Gaúchos. Este povoado era situado à beira do rio Arinos, e se formou a partir de 1956, devido a um projeto de colonização idealizado pela Colonizadora Noroeste Mato-grossense S/A. Era constituído, quase que exclusivamente, por descendentes alemães oriundos do Rio Grande do Sul e Santa Catarina, que trouxeram consigo seus hábitos, valores, tradições e modelos de produção (SELUCHINESK, 2008).

A explosão demográfica na região amazônica do Mato Grosso foi ocasionada pela expansão da fronteira agrícola através do Programa de Integração Nacional, que tinha como meta principal promover a "integração nacional", devassando os "espaços vazios" da Amazônia e exterminando as tensões sociais. A partir daí foram construídas as rodovias Transamazônica, estabelecendo uma conexão entre as regiões Nordeste e Norte, e a Cuiabá-Santarém (BR 163), que fez a conexão do Centro-Sul ao Norte do país (SELUCHINESK, 2008). Preocupado com a integração da região ao restante do país, o governo adotou uma agressiva política de ocupação e colonização. Essa política, na realidade, não tinha por finalidade apenas retirar a Amazônia brasileira do isolamento ao qual se encontrava, mas era motivada por fins econômicos (RIBEIRO, 2003).

A construção da BR 163 foi, desde o início, marcada pela violência e pelo grande derramamento de sangue. Índios, posseiros, soldados, colonos, colonizadores e garimpeiros lutavam, a todo custo, por seus ambiciosos interesses, provocando grandes conflitos pela posse de terra. Além dos impactos sociais, a construção desta rodovia gerou grandes impactos ambientais, pois além da retirada da vegetação para a abertura da estrada, o aumento da ocupação e das demais atividades humanas desencadeou um processo de esgotamento dos recursos naturais ali disponíveis (JATENE, 1983).

No final da década de 1970, muitos municípios já tinham se formado na região, mas ainda havia muita terra disponível. Em contrapartida, os conflitos pela posse de terra na região sul do Brasil estavam a todo vapor. Tal fato contribuiu para a continuidade do processo migratório, mesmo diante das adversidades impostas pela violência e falta de organização da colonização da Amazônia matogrossense. Motivados pelo sonho de encontrar uma boa terra para criar seus filhos ou apenas pela ambição de possuir sempre mais, os colonos encontraram nesta região a possibilidade real de crescimento econômico e estabelecimento de suas 
famílias, e, mesmo diante das dificuldades, prevaleceram e permaneceram nos projetos de colonização, ocupando definitivamente a região (SELUCHINESK, 2008).

Esses colonos possuíam famílias numerosas, com uma média de oito pessoas/família. Tal característica era favorável, no que se dizia respeito à mão de obra. Além disso, a oportunidade de expansão, e até mesmo aquisição de novas propriedades, estimulava a continuidade do vínculo familiar, uma vez que os filhos casados tinham a oportunidade de continuar trabalhando na mesma propriedade ou em terras próximas. Isto contribuiu para o enraizamento das tradições sulistas, que são baseadas em estreitos laços familiares. Com isso, as áreas de fronteira da Amazônia Legal no Mato Grosso foram intensamente povoadas (OLIVEIRA, 1997).

Este processo de expansão da fronteira na Amazônia Legal iniciouse pela ocupação do território por pequenos agricultores e foi impulsionado, alguns anos depois, pela exploração madeireira, pecuária e pelo cultivo de soja, milho e algodão, inserindo a região na economia nacional como importante exportadora de produtos primários. Como a ocupação se deu principalmente pela migração de populações oriundas do Centro-Sul e Nordeste, a influência dos modelos de desenvolvimento impôs à região um tipo de organização parecido com os padrões desenvolvimentistas do Sul e Sudeste brasileiros, limitando as possibilidades de um desenvolvimento autossustentável (CAMPOS, s.d.). Este novo padrão de desenvolvimento, visto principalmente na região norte do estado de Mato Grosso, possibilitou a penetração de novas atividades econômicas num espaço preexistente (SELUCHINESK, 2008).

Passos (2000) destaca que a partir da década de 1970, o estado de Mato Grosso foi incorporado de maneira intensa à economia nacional, tendo grande destaque a produção de grãos. A colonização privada se sobrepôs aos outros tipos de colonização (oficial e espontânea); e as bases para uma agricultura capitalista, tendo a soja como "carro chefe", foram estabelecidas. Sabe-se que os governos militares proporcionaram a implantação de toda uma infraestrutura no país, e que tal fato gerou maior dinamização econômica. Porém, as ações destes governos giraram apenas em torno da esfera econômica, em detrimento das questões relacionadas às esferas social e ambiental.

As características deste processo de ocupação, aliadas à expansão dos sistemas de produção intensivos, prejudicaram a agricultura familiar, gerando uma desigualdade social, frente às discrepâncias relacionadas à competitividade de mercado e acesso a créditos. Isto levou a um cenário repleto de focos de tensão social no território mato-grossense, expresso nas mudanças ocasionadas 
na dinâmica da mobilidade populacional. Além disso, como consequência desta forma de ocupação, surgiram muitos municípios nas zonas fronteiriças, como é o caso do conhecido "nortão" do Mato Grosso. Muitos desses municípios sofrem com o isolamento geográfico e a falta de infraestrutura adequada, e a cada dia se tornam menos atrativos aos investidores (CUNHA, 2006). A economia do Mato Grosso está fortemente ligada à agricultura, à pecuária extensiva e à exploração de madeira. O estado é considerado um dos principais produtores agrícolas do Brasil, sendo o maior produtor de soja (5,075 milhões de hectares) e de algodão (560 milhares de hectares), e o segundo maior produtor de milho (1,65 milhão de hectares) (IBGE, 2008).

Distante dos principais portos de exportação (Santos e Paranaguá), o Mato Grosso, em um primeiro momento, foi considerado unicamente um espaço de produção. Atualmente, muitas indústrias de transformação são implantadas na região, com a finalidade de agregar valor à produção e de atrair mão de obra mais qualificada. Como exemplos, podem ser citados os seguintes polos agroindustriais: cana/biodiesel (Tangará da Serra e Rondonópolis), soja (Rondonópolis), carne bovina (Alta Floresta e Colíder), suína (Nova Mutum) e aves (Lucas do Rio Verde) (FRANÇA, 2009).

\section{A COLONIZAÇÃO DE ALTA FLORESTA}

Alta Floresta é um município que se situa na depressão da Amazônia Meridional e está localizado na mesorregião do norte mato-grossense, microrregião de Alta Floresta (CASTRO, 2008). Sua população foi formada inicialmente por pequenos agricultores do Sul e Sudeste, e por garimpeiros que vieram principalmente do Norte e Nordeste do país (SELUCHINESK, 2008). Sua história foi marcada por uma colonização particular dirigida, que mobilizou um grande contingente de migrantes para a região.

A colonizadora Indeco S/A (Integração, Desenvolvimento e Colonização), administrada por Ariosto da Riva, foi a responsável pelo projeto de colonização da Gleba Indeco, que deu origem ao município de Alta Floresta. Além desse, outros projetos de colonização foram executados na região, formando os municípios de Carlinda, Paranaíta, Apiacás, Nova Monte Verde e Nova Bandeirantes, todos pertencentes ao polo de Alta Floresta (JATENE, 1983).

A empresa iniciou a ocupação efetiva da região no ano de 1973 , onde foram construídos, na primeira etapa, $142 \mathrm{~km}$ de uma estrada que ligaria a cidade ao quilômetro 642 da BR 163. Já na segunda etapa, foram construídos a 
escola, a igreja, o hospital e as ruas, e demarcados os lotes rurais e urbanos. O loteamento foi feito de forma a contemplar o estabelecimento de três categorias de empreendimentos rurais: exploração agrícola - regime de agricultura familiar; exploração agrícola - regime empresarial (pequenos e médios empreendimentos); e exploração agroflorestal ou agropecuária de grande porte. Os escritórios de vendas foram estabelecidos no sul do país, principalmente no estado do Paraná. No ano de 1976, com a finalização da construção da estrada, chegaram os primeiros colonos. No princípio, Alta Floresta era constituída por pequenos agricultores que vieram do Paraná, sendo a maioria de descendência italiana, que, seguindo suas origens, iniciaram a produção agrícola, especialmente o cultivo de café (JATENE, 1983; SELUCHINESK, 2008).

Para estimular a expansão da cafeicultura, a colonizadora instalou viveiros com capacidade para 30.000 mudas, as quais foram distribuídas aos colonos gratuitamente, e forneceu assistência técnica aos produtores que, entusiasmados pelas facilidades, investiram em projetos de produção agrícola na localidade (JATENE, 1983). Porém, depois de constatarem que a cafeicultura não era adequada para a região (em termos de produtividade, qualidade do produto e lucratividade), começaram a procurar algumas alternativas, como o cultivo de arroz, feijão, milho, guaraná e cacau (SOUZA, 2006).

O baixo lucro gerado pela agricultura fez com que os colonos abandonassem as suas propriedades e fossem para os garimpos em busca de ouro. Tal fato se consolidou como uma ameaça para os colonizadores, uma vez que tinham o objetivo de comercializar as terras; e os garimpeiros, ao contrário dos colonos, não desejavam comprar terras, mas apenas explorar seus recursos minerais. Por isso, Ariosto da Riva criou e disseminou uma imagem negativa dos garimpeiros, tornando-os inimigos dos colonos e gerando um conflito armado entre eles. Isto levou a uma intervenção federal na região, provocando a morte e expulsão de muitos garimpeiros. Mesmo assim, muitos garimpeiros continuaram a explorar a região, culminando na aceitação do garimpo pelos colonizadores (SELUCHINESK, 2008).

A extração do ouro fez a cidade crescer demasiadamente, tornando-a um importante polo regional. Porém, na década de 1990, a atividade garimpeira experimentou um forte declínio, devido ao esgotamento do recurso e pela queda do preço internacional do ouro. Com isso, veio a decadência do município, que tentou se reconstituir através da ideia inicial de produção agropecuária. Os lucros advindos do garimpo foram utilizados para suprimir a vegetação, ação necessária para formação das pastagens e aquisição de gado. Estabeleceu-se, desta forma, a atividade econômica mais importante do município: a pecuária de corte e leite. 
Juntamente com esta atividade, a agricultura familiar e a extração de madeira formaram a nova base da economia local (CASTRO et al. 2008). Atualmente, cerca de $60 \%$ do território municipal é constituído por pequenas propriedades rurais (IBGE, 2011), evidenciando a importância da agricultura familiar para o município.

Outra atividade econômica que se destaca em Alta Floresta é a industrialização, fortalecida pela implantação de laticínios, frigoríficos e de uma cooperativa de produção de polpa de frutas. Além disso, nota-se um esforço no sentido de conduzir a transformação da região em um polo turístico, priorizando os aspectos ecológicos das riquezas naturais (matas, rios etc.) e incentivando o artesanato local.

\section{SISTEMAS DE PRODUÇÃO}

Os sistemas de produção agrícola na Amazônia datam de 4.000 a 1.000 anos atrás, época em que as populações antigas da região começaram a explorar e domesticar produtos primários para sua subsistência. O conhecimento adquirido por estas populações durante séculos de manejo é uma importante fonte de informação sobre o sistema agrícola local, inclusive sobre as práticas tradicionais. Esse conhecimento popular fez com que os atuais agricultores cultivassem várias espécies em ambientes distintos (SANTOS et al. 2009).

Nas últimas décadas, a cobertura vegetal dos trópicos diminuiu acentuadamente em função do crescimento acelerado de áreas para cultivos agrícolas e pastagens. Após quatro décadas de intensificação da ocupação humana na Amazônia, o padrão de uso do solo desta área possui as seguintes características: (i) as áreas de cultivo de soja se destacam no Mato Grosso e, em menor escala, em Santarém; (ii) a agricultura familiar e os sistemas agroflorestais têm maior destaque na área da BR-230 (entre Altamira e Ruropólis); (iii) as populações tradicionais; iv) arroz e milho têm maior importância no extremo norte do Mato Grosso, onde a soja ainda não ocupou as terras agrícolas disponíveis; (v) a atividade madeireira está em expansão no Pará e em ligeiro declínio no Mato Grosso; e (vi) a pecuária ocupa extensas áreas, mas tem uma baixa produtividade (BRASIL, 2004).

Dentro desse contexto, destacam-se os seguintes sistemas de produção: Sistema de Plantio Direto (SPD); Sistema Convencional de Cultivo (SCC); Rotação de culturas; Sistemas Agroflorestais (SAFs) e a Agricultura Familiar. O atual sistema de exploração agrícola desta região tem induzido o solo a um 
processo acelerado de degradação. Os fatores que causam essa degradação agem de forma conjunta, e a importância relativa de cada um varia de acordo com as características climáticas, edáficas e das espécies cultivadas. Dentre esses fatores destacam-se a compactação, a ausência da cobertura vegetal do solo, a ação das chuvas de alta intensidade, o uso de áreas inaptas para culturas anuais, o preparo do solo com excessivas gradagens superficiais e o uso de práticas conservacionistas isoladas (EMBRAPA, 2011).

Em substituição a esse modelo, deve-se dar prioridade ao uso do Sistema de Plantio Direto (SPD), que envolve uma técnica de cultivo conservacionista, na qual não há preparo convencional de aração e gradagem, procurando manter o solo com restos de vegetais que reduzem a temperatura, o impacto das gotas da chuva, a lixiviação e a insolação direta. De acordo com Reis (2006), o SPD é caracterizado pela permanência de palha vegetal, consorciação de culturas e resíduos de vegetais na superfície do solo, que posteriormente são revolvidos apenas na fileira de deposição de sementes e fertilizantes, com o controle de plantas daninhas realizado com a aplicação de herbicidas e pelos efeitos alelopáticos de cada planta de cobertura.

É importante ressaltar que o SPD é o sistema mais adequado para produções em larga escala. No entanto, é possível adotar o Sistema Convencional de Cultivo, que consiste em um método agrícola que proporciona uma maior produtividade através da utilização intensa de insumos externos e que, em curto prazo, traz resultados econômicos visíveis, como o aumento da produtividade e a eficiência agrícola (EMBRAPA, 2011). Souza (2005) relata que o aumento da produtividade contribui para a diminuição da migração rural e melhora a distribuição de renda. Porém, em longo prazo, traz danos ambientais que não são contabilizados pelos adeptos da agricultura convencional, como também são inseridos aparatos tecnológicos que substituem progressivamente a mão de obra empregada.

A rotação de culturas é uma técnica conservacionista que consiste na exploração de mais de uma cultura, proporcionando ao agricultor o aproveitamento dos recursos disponíveis em sua propriedade e a racionalização do uso dos fatores de produção de maneira que cada espécie possa se desenvolver sem prejudicar o desenvolvimento das mesmas, delimitando o espaço físico, químico e biológico de maneira adequada. A associação das culturas de milho e feijão é a mais empregada, em razão dos feijoeiros possuírem um ciclo vegetativo curto e pouco competitivo, podendo ser semeados em diferentes épocas, e de adaptarem-se bem ao cultivo consorciado, além do feijão ser um dos alimentos básicos do povo brasileiro. As leguminosas contribuem na fixação de nitrogênio, 
enriquecendo o solo; já as gramíneas contribuem na estruturação do solo, evitando a perda de nutrientes por lixiviação.

Os Sistemas Agroflorestais compreendem a associação de culturas perenes (espécies frutíferas nativas) e/ou espécies florestais, constituindo um sistema do tipo silviagrícola consorciado, com a intercalação eventual de culturas anuais alimentares e complementado ocasionalmente pela criação de animais (SILVA et al., 2010). Tal sistema visa obter a racionalização e o melhor aproveitamento do uso dos recursos naturais envolvidos no sistema de produção (YARED et al.,1998).

Já a agricultura familiar é uma forma de produção estruturalmente diversificada, o que constitui um mecanismo de adequação não só ao meio ambiente, como também às intempéries do mercado e à forma de organização do trabalho familiar (COSTA, 1997). Segundo o Censo Agropecuário de 2006 (IBGE, 2009), a agricultura familiar representava cerca de $84,4 \%$ das propriedades brasileiras, produzindo geralmente alimentos voltados para a cesta básica.

Considerando a representatividade desses sistemas de produção na Amazônia brasileira, é de extrema importância que se conheça o histórico das antigas populações dessas áreas, para que seja possível criar e gerir sistemas produtivos sustentáveis baseados nos princípios ecológicos, socioeconômicos e culturais, inclusive a forma de como os agricultores tratam as plantas ou animais para obter a produção de alimentos, de fibras ou de outros produtos agrícolas.

\section{IMPACTOS NA CONSERVAÇÃO AMBIENTAL}

A expansão das atividades agrícolas na região amazônica tem gerado alterações significativas na composição e formas de uso do solo e demais recursos naturais. A crescente mecanização e os incentivos governamentais voltados à expansão agropecuária contribuíram para a transformação de vastas extensões de terras em regiões produtoras de grãos e criação de gado, resultando em impactos negativos sobre o meio ambiente. Dentre esses impactos destacam-se a perda da biodiversidade local, a destruição da vegetação nativa, as consequências continentais em termos de abastecimento e qualidade da água, a liberação de grandes quantidades de $\mathrm{CO}_{2}$ na atmosfera, a erosão, compactação e o empobrecimento do solo (HOGAN et al., 2002).

A Amazônia brasileira abriga um grande número de espécies, embora muitas ainda não tenham sido descritas. Segundo Fearnside (2006), esta biodiversidade tem valor significativo em termos de utilidade tradicional e de valor de existência, 
pois se apresenta como uma fonte de alimentos, fibras, medicamentos e demais recursos, e precisa existir para ser explorada. A perda desta diversidade, oriunda da destruição e fragmentação de habitats, resulta em uma redução da qualidade de vida, pois reflete diretamente na oferta e distribuição de água potável, no aumento de doenças e epidemias, na qualidade e produção de alimentos e na vulnerabilidade a desastres ambientais. Desta forma, a perda da diversidade biológica na Amazônia pode desencadear uma série de crises, as quais podem ter efeitos (regionais e globais) negativos e irreversíveis sobre o meio ambiente.

A conversão de florestas em agroecossistemas continua aumentando na Amazônia (PEREIRA; VIEIRA, 2001). Alguns dados apontam que esta conversão contribui com aproximadamente $24 \%$ das emissões mundiais de $\mathrm{CO}_{2}, 55 \%$ das emissões de $\mathrm{CH}_{4}$ e $85 \%$ das emissões de $\mathrm{N}_{2} \mathrm{O}$ para a atmosfera, gerando efeitos como a menor assimilação de carbono, pela redução da massa fotossintética viva (CAMPOS, 2006; IPCC, 2007). Estima-se que 20\% do incremento anual das perturbações no balanço entre as radiações solar incidente e infravermelho emergente na atmosfera tem origem no setor agrícola, considerando-se o efeito desses três gases nas alterações climáticas globais (BUCKERIDGE, 2008). As principais estratégias para mitigar a emissão de tais gases consistem na redução das taxas de desmatamento e de queima de material vegetal, no manejo adequado do solo e na maximização do sequestro de carbono no solo e na vegetação. Por isso, a conservação das florestas na Amazônia tem sido considerada uma das principais formas de mitigação do aquecimento global (BRUN, 2007). O desmatamento nesta região é determinado por vários fatores, que estão inter-relacionados e devem ser percebidos em diferentes contextos históricos e geográficos.

As taxas de desmatamento estão diretamente relacionadas às forças econômicas, o que explica as variações que ocorreram ao decorrer dos anos. Segundo dados do INPE (2011), as taxas de desmatamento na Amazônia aumentaram significativamente a partir de 1995, ano marcado pelo maior índice de devastação da vegetação amazônica. Tal fato deve-se à criação do Plano Real, que resultou em um aumento dos investimentos no setor agropecuário, devido à estabilização da moeda nacional. Por outro lado, os índices de desmatamento sofreram uma forte queda a partir de 2005, resultado de taxas de câmbio desfavoráveis para a exportação, combinadas com a repressão da exploração madeireira e a criação de Unidades de Conservação (FEARNSIDE, 2006). Ainda assim, o desmatamento na Amazônia é um fator preocupante, uma vez que resulta em perda de diversidade biológica, modificações no balanço hídrico e na disponibilidade de nutrientes, aumentos da temperatura atmosférica e aceleração de processos erosivos (KRUSCHE et al., e KINGO 2005).

Novos Cadernos NAEA • v. 16 n. 1 • p. 173-190 • jun. 2013 
Em regiões onde a atividade agrícola se baseia no plantio de monoculturas, como é caso de algumas regiões da Amazônia, a transformação de florestas nativas para fins agrícolas é uma prática que ocasiona grandes perdas de $\mathrm{C}$ devido ao desmatamento e degradação da biomassa vegetal. Além disso, o revolvimento excessivo do solo proporciona quedas nos estoques de MOS e, consequentemente, de CO e NT, uma vez que, mesmo com elevadas adições de $\mathrm{C}$ e $\mathrm{N}$ via resíduos, as perdas são normalmente superiores às adições (LOVATO, 2001). Além disso, a abertura de novas áreas para a implantação de monoculturas consiste em dois momentos de forte emissão de $\mathrm{CO}_{2}$ : um no desmatamento seguido da queimada e outro no preparo do solo. O preparo do solo pela aração pode resultar em até $81,3 \mathrm{~g} \mathrm{CO}_{2} \mathrm{~m}^{2}$ emitidos para a atmosfera num período de 5 $\mathrm{h}^{17}$. Além disso, a aração do solo, seguida de várias gradagens, predispõe o solo à erosão hídrica, agravando ainda mais a situação, uma vez que a erosão causada pelas chuvas é responsável por emissão líquida anual de aproximadamente $1 \mathrm{Gt}$ $\mathrm{C}^{18}$ (MACHADO, 2005).

Segundo dados da SEMA/MT (2007), a área desmatada no município de Alta Floresta corresponde a 51,75\% do seu território total. Tal índice está diretamente relacionado ao desenvolvimento de atividades como a agricultura de grãos, a pecuária intensiva, a extração madeireira e o garimpo. Entre 2001 e 2008, a taxa de desmatamento do município foi de 3,1\%, e aproximadamente $70 \%$ deste valor foi proveniente de desmatamentos que apresentaram polígonos maiores do que 100 ha, indicando a predominância de grandes desmatadores, principalmente nas regiões noroeste e leste do município (LIMA; NÓBREGA, 2009).

Conforme Castro et al. (2008), a atividade pecuária em Alta Floresta é predatória e intensifica o processo de desertificação. Barros et al. (2002) afirmam que Alta Floresta foi o município mato-grossense que apresentou a maior taxa de evolução do rebanho efetivo na década de 1990. Os impactos negativos mais expressivos desta atividade estão relacionados ao superpastoreio, que intensifica a compactação do solo e subtrai a cobertura vegetal. O sistema de exploração adotado, aliado ao porte e carga animal, à disponibilidade de recursos e ao tipo de solo, influencia a intensidade desses impactos. Além disso, a produção animal aumenta a concentração de resíduos líquidos e sólidos e, consequentemente, o risco de contaminação das águas subterrâneas e superficiais (LEITE et al., 2011). 


\section{CONSIDERAÇÕES FINAIS}

O avanço da fronteira agrícola sobre a Amazônia brasileira tem causado, desde o início, intensos impactos ambientais e socioeconômicos na região. Os processos de ocupação e as formas de exploração dos recursos sempre foram baseados na usura e ambição do Estado e dos colonizadores, que, por sua vez, nunca estiveram interessados em conservar a inestimável biodiversidade local. A colonização dirigida, embora não tenha atingido todos os seus objetivos, ofereceu aos pequenos produtores acesso aos meios de produção, inserindo-os, seletivamente, em um novo contexto econômico e social.

A integração de novos atores sociais, associada ao fortalecimento da economia externa, propiciou o surgimento de diferentes faces produtivas, caracterizando a Amazônia como um importante polo econômico, mas marcado pela extrema desigualdade social e devastação ambiental. A distribuição fundiária qualitativamente diferenciada contribuiu para a heterogeneidade socioeconômica, espacial e cultural da Amazônia. Este cenário, agravado pela ausência de articulações políticas eficazes, representa o estado caótico das condições sociais e ambientais da região. Desta forma, torna-se necessária a aplicação dos dispositivos legais referentes à política da reforma agrária, de forma a minimizar as distorções impostas pelo histórico de colonização e exploração regional.

\section{REFERÊNCIAS}

BARROS, G.S. de C.; ZEN, S. de; BACCHI, M.R.P.; ICHIARA, S.M.; OSAKI, M.; PONCHIO, L.A. Economia da pecuária de corte na região norte do Brasil. Piracicaba: Cepea; Esalq/USP, 2002.

BRASIL. Coordenação da Casa Civil da Presidência da República. Plano de desenvolvimento sustentável para a Área de influência da BR-163. Brasília, DF, 2004. 44p.

BRUN, F.G.K. Dinâmica do carbono orgânico em espécies arbóreas de uma Floresta Estacional Decidual no Rio Grande do Sul. 2007. 107f. Dissertação (Mestrado em Engenharia Florestal) - Centro de Ciências Rurais, Universidade Federal de Santa Maria, Santa Maria, 2007.

BUCKERIDGE, M.S. Biologia e Mudanças Climáticas no Brasil. São Carlos: RiMa, 2008. 
CAMPOS, B.-H.C. de. Dinâmica do carbono em Latossolo Vermelho sob sistemas de preparo do solo e de culturas. 2006. 190f. Tese (Doutorado em Ciência do Solo) - Centro de Ciências Rurais, Universidade Federal de Santa Maria, Santa Maria, 2006.

CAMPOS, Í. A sustentabilidade da agricultura na Amazônia. Produto parcial suscitado pela pesquisa sobre desenvolvimento agroindustrial na Amazônia. Belém: UFPA/NAEA. [s.d.]. 13p. Em desenvolvimento.

CASTRO, S.M.; SIERPE, R.; CASTILHOS, Z.C.; EGLER, S.G. Ecorregião Xingu-Tapajós: principais vetores do desmatamento no município em Alta Floresta, MT. In: ENCONTRO DA ENGENHARIA AMBIENTAL, 1., 2008, Rio de Janeiro. Anais... Rio de Janeiro: UFRJ, 2008.

CUNHA, J.M.P. da; ALMEIDA, G.M.R. de; RAQUEL, F.; CARVALHO, P. Diagnósticos regionais do Estado do Mato Grosso. Campinas: UNICAMP/ Núcleo de Estudos de População 2004. p.225. (TEXTO NEPO, 49).

CUNHA, J. M.P. da. Dinâmica migratória e o processo de ocupação do CentroOeste brasileiro: o caso de Mato Grosso. Rev. Bras. Est. População, São Paulo, v. 23, n. 1, p. 87-107, 2006.

COSTA, F. de A. Diversidade Estrutural e Desenvolvimento Sustentável, In: XIMENES, T. (Org.) Perspectivas do Desenvolvimento Sustentável. Belém: NAEA/UFPA, 1997.

EMBRAPA - Tecnologias de Produção de Soja - Região Central do Brasil 2012 e 2013. Londrina: Embrapa Soja, 2011. 261p. Disponível em: < http:// www.cnpso.embrapa.br/download/SP15-VE.pdf> Acesso em: 10 set. 2012.

EMBRAPA- Empresa Brasileira de Pesquisa Agropeciuária. Tecnologias de Produção de Soja - Região Central do Brasil 2012 e 2013. Disponível em: <http://www.cnpso.embrapa.br/download/SP15-VE.pdf> Acesso em: 10 set. 2012.

FRANÇA, B.R. Conhecendo a Amazônia - dinâmicas territoriais no Mato Grosso 2009. Disponível em: <http://each.uspnet.usp.br/amazonia/projeto. htm> Acesso em: 19 set. 2012.

FEARNSIDE, P.M. Desmatamento na Amazônia: dinâmica, impactos e controle. Acta Amazônica, Manaus, v. 36, n. 3, p. 395-400, 2006.

HOGAN, D. J.; CARMO, R.L. do; AZEVEDO. A.M.M. de; GAMA, I.; DARCIE, C.; DELGADO, C. C. Um breve perfil ambiental da região Centro-Oeste: 2000 . 
HOGAN, D.J.; CUNHA, J.M.P. da; CARMO, R.L. Uso do solo e mudança de sua cobertura no Centro-Oeste do Brasil: consequências demográficas, sociais e ambientais. In: Migração e Ambiente no Centro-Oeste. Campinas: Cnpd/ Abep/Nepo, 2002.

HOMMA, A.; KINGO, O. A dinâmica do extrativismo vegetal na Amazônia: uma interpretação teórica. Belém: EMBRAPA-CPATU, 1990. 38p. (Documentos, 53).

HUERTAS, D.M. Da fachada atlântica à imensidão amazônica: fronteira agrícola e integração territorial. São Paulo: Annablume, 2009.

IBGE-Instituto Brasileiro de Geografia e Estatística. Censo Agropecuário 2006: IBGE, 2009. Disponível em: < http://ibge.gov.br/home/estatistica/economia/ agropecuaria/censoagro/default.shtm> Acesso em: 19 set. 2012.

. Instituto Brasileiro de Geografia e Estatística. Sidra: Sistema IBGE

de Recuperação Automática: IBGE, 2008. Disponível em: http://www.sidra. ibge.gov.br> Acesso em: 16 set. 2012.

Cidades. Rio de Janeiro, 2011. Disponível em: < http:/ /www.ibge.gov. br/cidadesat/topwindow.htm?1>. Acesso em: 01 set. 2012.

INPE - Instituto Nacional de Pesquisas Espaciais. Projeto PRODES: INPE, 2011. Disponível em: < http://www.obt.inpe.br/prodes/prodes_1988_2011. htm> Acesso em: 25 ago. 2012.

IPCC-Intergovermmental Panel on Climate Change. Climate Change 2007: The Physical Science Basis. Summary for Policymakers. Disponível em: < http:// www.ipcc.ch/SPM2feb07.pdf.2007>. Acesso em: 25 ago. 2012.

JATENE, H. da S. Reabertura da fronteira sobre controle: a colonização particular dirigida de Alta Floresta. 1983. 173f. Dissertação (Mestrado em Sociologia) - Instituto de Filosofia e Ciências Humanas, Universidade Estadual de Campinas, 1983.

KRUSCHE, A. V.; BALLESTER, M. V. R.; VICTORIA, R. L.; BERNARDES, M. C.; LEITE, N. K.; HANADA, L.; VICTORIA, D. C.; TOLEDO, A. M.; OMETTO, J. P.; MOREIRA, M. Z.; GOMES, B. M.; BOLSON, M. A.; NETO, S. G.; BONELLI, N.; DEEGAN, L.; NEILL, C.; THOMAS, S.; AUFDENKAMPE, A. K.; RICHEY, J.E. Efeitos das mudanças do uso da terra na biogeoquímica dos corpos d’água da bacia do rio Ji-Paraná, Rondônia. Acta Amazônica, v. 35, n. 2 , p. 197-205, 2005. 
LEITE, S.P.; SILVA, C.R. da; HENRIQUES, L.C. Impactos ambientais ocasionados pela agropecuária no Complexo Aluízio Campos. Rev. Bras. de Informações Científicas, v. 2, n. 2, p. 59-64, 2011.

LIMA, A.; NÓBREGA, B. Indicadores socioeconômicos e espaciais dos municípios prioritários para o controle do desmatamento no Estado do Mato Grosso. [s.1.]: IPAM, 2009.

LOUREIRO, V.R. Amazônia: uma história de perdas e danos, um futuro a (re) construir. Estudos Avançados, São Paulo, v. 16, n. 45, p.127-121, 2002.

LOVATO, T. Dinâmica do carbono e nitrogênio do solo afetada por preparos do solo, sistemas de cultura e adubo nitrogenado. 2001. $133 \mathrm{f}$. Tese (Doutorado em Ciência do solo) - Centro de Ciências Rurais, Universidade Federal de Santa Maria, Santa Maria, 2001.

MACHADO, P.L.O. de A. Carbono do solo e a mitigação da mudança climática global. Química Nova, São Paulo, v. 28, n. 2, p.329-334, 2005.

OLIVEIRA, A.U. de. A Fronteira Amazônica Mato-Grossense: grilagem, corrupção e violência. 1997. 496f. Tese (Livre-Docência) - Faculdade de Filosofia, Letras e Ciências Humanas, Universidade de São Paulo, São Paulo, 1997.

PASSOS, M.M. dos. A construção da paisagem no Mato Grosso-Brasil. Presidente Prudente: Programa de Pós-graduação em Geografia, 2000.

PEREIRA, C.A.; VIEIRA, I.C.G. A importância das florestas secundárias e os impactos de sua substituição por plantios mecanizados de grãos na Amazônia. Interciencia, Caracas, v. 26, n. 8, p. 337-341, 2001.

PERIPOLLI, O. J. Amaciando a terra - o projeto Casulo: um estudo sobre a política educacional dos projetos de colonização do Norte de Mato Grosso. 182f. 2002. Dissertação (Mestrado em Educação) - Faculdade de Educação, Universidade Federal do Rio Grande do Sul, 2002.

PROCÓPIO, A. Destino amazônico. São Paulo: Hucitec, 2005.

REIS, G.N. dos R., FURLANI, C.E.A; SILVA, R.P. da; GERLACH, J.R.; CORTEZ, J. W; GROTTA, D.C.C. Decomposição de culturas de cobertura no sistema plantio direto, manejadas mecânica e quimicamente. Eng. Agríc., Jaboticabal, v.27, n.1, p.194-200, 2006.

RIBEIRO, U.F.; LEOPOLDO, P.R. Colonização ao Longo da Transamazônica: Trecho Km 930 - 1035. Revista Eletrônica de Agronomia, v. 2, n.3, 2003. 
SANTOS, J.L. dos; SILVA, M.F. da; PEREIRA, H. dos S. Uso e diversidade de espécies cultivadas na Reserva Desenvolvimento Sustentável do Tupé, Manaus, Amazonas, Brasil. Manaus: INPA, 2009. 18p.

SANTOS, R.A. de O. História econômica da Amazônia. 1800 - 1920. São Paulo: Queiroz, 1980.

SELUCHINESK, R.D.C. De heróis a vilões: imagem e auto-imagem dos colonos da Amazônia mato-grossense. 2008. 263f. Tese (Doutorado em Política e Gestão Ambiental) - Centro de Desenvolvimento Sustentável, Universidade de Brasília, Brasília, DF, 2008.

SEMA/MT-Secretaria de Estado do Meio Ambiente do Mato Grosso. Desmatamento. Cuiabá, 2007. Disponível em: <http://www.sema.mt.gov.br/ images/stories/templates/Desmate_por_Munic_ate_2007.jpg >. Acesso em: 10 set. 2012.

SILVA, R.G. da; ALMEIDA, E.S.; MARCIEL, R.C.G. Dinâmica da modernização em sistemas de produção familiar rural na amazônia sul ocidental. Juíz de Fora: UFJF/ Programa de Pos-Graduação em Economia Aplicada, 2010. 22p.

SOUZA, S.C. Desmatamento e clima em Alta Floresta - Amazônia matogrossense. 2006. 92f. Dissertação (Mestrado em Geografia) - Instituto de Ciências Humanas e Sociais, Universidade Federal de Mato Grosso, Cuiabá, 2006. SOUZA, N.S. A Amazônia brasileira: processo de ocupação e a Devastação da floresta. Brasília, DF, 2010. (Boletim Científico ESMPU)

SOUZA, N. de J. de. Desenvolvimento Econômico. 5. ed. São Paulo: Atlas, 2005.

YARED, J.A.G.; BRIENZA JÚNIOR, S.; MARQUES, L.C.T. Agrossilvicultura: conceitos, classificação e oportunidades para a aplicação na Amazônia brasileira. Belém: Embrapa-CPATU. 1998. p.39. (Documento 104). 